\title{
Preserved Versus Preservative-Free Latanoprost for the Treatment of Glaucoma and Ocular Hypertension: A Post Hoc Pooled Analysis
}

\author{
Paul Harasymowycz $\cdot$ Cindy Hutnik · Jean-François Rouland • \\ Francisco J. Muñoz Negrete · Mario A. Economou • Philippe Denis • \\ Christophe Baudouin
}

Received: January 28, 2021 / Accepted: March 25, 2021 / Published online: April 23, 2021

(c) The Author(s) 2021

\section{ABSTRACT}

Introduction: To compare the tolerability and efficacy of a preservative-containing latanoprost (PCL) to a preservative-free formulation of

P. Harasymowycz $(\bowtie)$

University of Montreal, Montreal, Canada

e-mail: pavloh@igmtl.com

P. Harasymowycz

Bellevue Ophthalmology Clinics and Montreal

Glaucoma Institute, Montreal, Canada

C. Hutnik

Ivey Eye Institute, Western University, London, ON, Canada

J.-F. Rouland

Ophthalmology Department, University of Lille, Lille, France

F. J. M. Negrete

Hospital Ramón y Cajal, Universidad Alcalá, Ophthalmology, Madrid, Spain

M. A. Economou

Queen Sofia Hospital, Stockholm, Sweden

M. A. Economou

Praktikertjänst, Stockholm, Sweden

P. Denis

Department of Ophthalmology, HEH, Hospices

Civils de Lyon, Lyon, France

C. Baudouin

Quinze-Vingts National Ophthalmology Hospital, Paris, France latanoprost (PFL) in patients with open-angle glaucoma or ocular hypertension.

Methods: A pooled analysis was performed of data from five published studies. The primary outcome was tolerability as evaluated by the severity of hyperemia. The secondary objectives were patient tolerance based on a composite ocular surface disease (OSD) score arising from ocular signs and symptoms, patient and investigator satisfaction, and a comparison of IOPlowering efficacy.

Results: There were three randomized controlled trials and two observational studies included in the analysis. Conjunctival hyperemia improved significantly in $25.6 \%$ (388) of patients switched to the PFL group versus $11.7 \%$ (117) of patients switched to the PCL group $(p<0.001)$. PFL was two times superior to PCL in reducing ocular hyperemia (odds ratio = 1.96; $p<0.001)$. The mean OSD composite score decreased by $32.2 \%$ in patients switched to the PFL group and $14.1 \%$ in the PCL group $(p<0.001)$. At 3 months, the mean IOP was similar between groups $(p=0.312)$.

Conclusion: This post hoc pooled analysis confirmed the findings of the individual studies that PFL is as efficacious at reducing IOP as PCL but better tolerated. After switching to PFL, there was twice the improvement in the OSD composite score. PFL was twice as effective at reducing ocular hyperemia and other ocular signs. These findings suggest that PFL has features that may improve patient compliance, 
thereby potentially improving the IOP-lowering efficacy on a long-term basis.

\section{PLAIN LANGUAGE SUMMARY}

Preservatives in eye drops for glaucoma can cause side effects such as stinging and eye redness. These side effects can cause some patients to reduce the frequency of the drops as prescribed or stop using the drops. One of the most common drops for glaucoma is latanoprost. This study evaluated whether a preservative-free latanoprost (PFL) is as effective as preservativecontaining latanoprost (PCL) for reducing eye pressure and whether PFL is better tolerated in patients with glaucoma. The results of the study indicated that PFL was as effective as PCL for reducing eye pressure. The results also indicated PFL was much better at reducing the side effects related to PCL. For example PFL reduces eye redness up to twofold compared to PCL. By reducing the side effects associated with PCL patients may continue to take their glaucoma drops as directed and thereby reduce the risk of vision loss from glaucoma.

Keywords: Open-angle glaucoma; Ocular hypertension; Hyperemia; Ocular surface disease; Intraocular pressure; Latanoprost; Preservative-free; $\quad$ Monoprost $^{\circledR}$; Patient satisfaction

\section{Key Summary Points}

Why carry out this study?

Preservative-containing glaucoma drops are associated with decreased patient compliance which may affect therapeutic efficacy over time and cause an undue public health burden.

This study compared the tolerability and efficacy of a preservative-containing latanoprost (PCL) to a preservative-free formulation of latanoprost (PFL) in patients with open-angle glaucoma or ocular hypertension. Better tolerability may lead to greater patient compliance.

\section{What was learned from the study?}

Preservative-free latanoprost and preservative-containing latanoprost were equally effective at reducing intraocular pressure. However, preservative-free latanoprost was better tolerated. The findings suggest that preservative-free latanoprost has features that may improve patient compliance, potentially improving long-term intraocular pressurelowering efficacy.

\section{DIGITAL FEATURES}

This article is published with digital features, including a summary slide to facilitate understanding of the article. To view digital features for this article go to https://doi.org/10.6084/ m9.figshare.14237282.

\section{INTRODUCTION}

Patients with glaucoma may require topical therapy much longer than previous generations because of the increasing life span of the population. Additionally, the prevalences of glaucoma and ocular surface disease (OSD) increase 
with age. Combined, these population dynamics indicate that mitigating OSD over the lifetime of a patient with glaucoma will be important for achieving successful outcomes. Preservatives in topical glaucoma medications have been associated with OSD [1]. Patients on long-term topical therapy that contains preservatives are at greater risk of OSD, dry eye, and ocular toxicity that may affect deeper ocular tissues in the anterior chamber angle and the retina [1-3]. Often, patients with glaucoma require lifetime topical therapy and OSD has been reported in up to $59 \%$ of patients $[4,5]$. Preservatives in topical antiglaucoma drops disrupt the ocular surface by a variety of mechanisms resulting in decreased tear film stability and increased evaporation $[6,7]$. The side effects of preserved eye drop administration include ocular hyperemia, burning, stinging, and itching that are exacerbated by an unstable tear film [7].

The effectiveness of topical glaucoma therapy depends on patient adherence to their treatment, yet nonadherence with the topical therapy regimen has been reported in up to $30 \%$ of patients with glaucoma [8]. Additionally, nonadherence doubles in patients with side effects associated with the treatment or among patients using preservative-containing drops [8]. This is clinically pertinent because of the surreptitious nature of glaucoma where patients may not experience any untoward signs or symptoms of halting or decreasing the frequency of eye drop administration. In fact, patients may associate decreasing or halting drops with greater comfort from the reduced conjunctival hyperemia, burning, and stinging [9].

Topical prostaglandin analogues (PGAs) are a common first-line therapy for lowering IOP in glaucoma and ocular hypertension [10]. The efficacy and safety of PGAs has been well documented [11, 12]. Currently the most commonly prescribed PGA for glaucoma is preserved latanoprost and its generic preserved formulation $[9,11,13-15]$. Latanoprost $\left(X^{2} a a_{a}{ }^{\circledR}\right.$; Pfizer Inc., New York, NY, USA) was the first PGA approved as first-line therapy for glaucoma and has an excellent systemic safety profile and there are a number of generic formulations available worldwide $[9,11,13-15]$. Preserved and preservative-free formulations represent $58 \%$ and $42 \%$, respectively, of the latanoprost market [9, 11, 13-15]. However, preservativefree formulations of latanoprost, such as Monoprost $^{\circledR}$ (Laboratoires Théa, Clermont-Ferrand, France), have been available since 2013 . Given the proven benefits of preservative-free topical therapy, including decreased ocular signs and symptoms of OSD and increased adherence, we performed a post hoc pooled analysis of randomized controlled clinical trials and real-world evidence observational studies that compared patient tolerance and efficacy of a preserved latanoprost $\left(\right.$ Xalatan $\left.^{\circledR}\right)$ to a preservative-free latanoprost $\quad\left(\right.$ Monoprost $^{\circledR}$ ) $[4,5,7,9,11,13,14]$. Combining data from randomized controlled trials and real-world observational studies produces more relevant estimators, reducing bias and addressing the drawbacks of each kind of study and may indicate improvements in patient care $[15,16]$.

\section{METHODS}

This post hoc pooled analysis integrated and reanalyzed the source data from three randomized clinical trials (two phase III studies and a phase IV study) and two international realworld evidence observational studies that compared preservative-containing latanoprost (PCL) and preservative-free latanoprost (Monoprost ${ }^{\circledR}$; PFL) (Table 1) $[9,11,13,14]$.

The source data from each of the five studies were acquired and reanalyzed in a new database. Each study was approved by the ethics review board in each country and adhered to the tenets of the Declaration of Helsinki and all relevant local regulations. As this is a review of data from previous studies, online registration as a clinical trial was not required.

\section{Primary Objective}

The primary objective was tolerance by the evaluation of conjunctival hyperemia with each topical treatment. Most of the studies included here graded conjunctival hyperemia with the McMonnies/Chapman-Davies (MC-D) scale and 
Table 1 Patient demographics of studies that compared preservative-free latanoprost to preserved latanoprost

\begin{tabular}{|c|c|c|c|c|c|c|}
\hline & \multirow[t]{2}{*}{ Overall } & \multicolumn{5}{|l|}{ Study } \\
\hline & & $\begin{array}{l}\text { LT2345-PIII } \\
{[13]} \\
\text { RCT }\end{array}$ & $\begin{array}{l}\text { PIV-0513 } \\
{[10]} \\
\text { RCT }\end{array}$ & $\begin{array}{l}\text { US-PIII } \\
\text { RCT }\end{array}$ & $\begin{array}{l}\text { FREE [8] } \\
\text { Observational } \\
\text { study }\end{array}$ & $\begin{array}{l}\text { PASSY }[12] \\
\text { Observational } \\
\text { study }\end{array}$ \\
\hline \multicolumn{7}{|l|}{ Gender } \\
\hline$n$ & 3610 & 404 & 192 & 428 & 714 & 1872 \\
\hline \multicolumn{7}{|l|}{ PFL } \\
\hline$n$ & & 214 & 137 & 166 & 356 & NA \\
\hline \multicolumn{7}{|l|}{ PCL } \\
\hline$n$ & & 190 & 55 & 169 & 290 & NA \\
\hline Male & $\begin{array}{l}1474 \\
\quad(40.83 \%)\end{array}$ & $203(50.2 \%)$ & $86(44.8 \%)$ & $\begin{array}{l}173 \\
(40.4 \%)\end{array}$ & $286(40.1 \%)$ & $726(38.8 \%)$ \\
\hline Female & $\begin{array}{l}2136 \\
\quad(59.17 \%)\end{array}$ & $201(49.8 \%)$ & $106(55.2 \%)$ & $\begin{array}{l}255 \\
\quad(59.6 \%)\end{array}$ & $428(59.9 \%)$ & $1146(61.2 \%)$ \\
\hline \multicolumn{7}{|c|}{ Age (years) } \\
\hline$n$ & 3317 & 404 & $\mathrm{NC}$ & 339 & 717 & 1857 \\
\hline $\begin{array}{r}\text { Mean } \\
(\mathrm{SD})\end{array}$ & $66.32(10.9)$ & $64.7(11.5)$ & NC & $67.1(10.6)$ & $66.7(10.9)$ & $66.8(12.1)$ \\
\hline \multicolumn{7}{|c|}{ Stratification of age (years) } \\
\hline$n$ & 3482 & 404 & 192 & 339 & 717 & 1857 \\
\hline $20-50$ & 260 & 40 & 18 & 20 & 45 & 164 \\
\hline $50-70$ & 1732 & 220 & 105 & 175 & 367 & 865 \\
\hline$>70$ & 1490 & 144 & 69 & 144 & 305 & 828 \\
\hline
\end{tabular}

$n$ number of patients, $N C$ data not collected, PIII phase III study, PIV phase IV study, $R C T$ randomized comparison trial, $S D$ standard deviation, $N A$ not applicable, $P C L$ preservative-containing latanoprost, $P F L$ preservative-free latanoprost

one study used the Efron scale [17]. To standardize the grading of conjunctival hyperemia, the Efron scale was converted to the MC-D scale as previously described and scored as absent (MC-D grade $0=$ grade 0 Efron), mild (MC-D grade 1 or 2 = grade 1 Efron), moderate (MC-D grade 3 = grade 2 Efron), and severe (MC-D grade 4 or $5=$ grade 3 or 4 Efron) [18].

\section{Secondary Objectives}

The secondary criteria for the evaluation of tolerance included a change in signs and symptoms of OSD with a reduction indicating an improvement in tolerability and increased OSD indicating lower tolerability. Tolerability was based on a composite OSD score integrating ocular signs and symptoms between instillation of drops, patient and investigator satisfaction, and ocular and systemic adverse events. For standardization of ocular signs and symptoms, a five-parameter OSD composite score (0-100) was calculated from weighted parameters: the five variables assessed for this composite score were weighted as follows: eyelid redness (15), eyelid swelling (15), corneal staining (25), 
Table 2 Summary of parameters in each study comparing preservative-containing latanoprost to preservative-free latanoprost

\begin{tabular}{|c|c|c|c|c|c|}
\hline & Study & & & & \\
\hline & $\begin{array}{l}\text { LT2345-PIII [13] } \\
\text { (randomized } \\
\text { comparison trial) }\end{array}$ & $\begin{array}{l}\text { US-PIII } \\
\text { (randomized } \\
\text { comparison trial) }\end{array}$ & $\begin{array}{l}\text { PIV-0513 [10] } \\
\text { (randomized } \\
\text { comparison trial) }\end{array}$ & $\begin{array}{l}\text { FREE }[8] \\
\text { (observational } \\
\text { study) }\end{array}$ & $\begin{array}{l}\text { PASSY [12] } \\
\text { (observational } \\
\text { study) }\end{array}$ \\
\hline Hyperemia & $\checkmark$ & $\checkmark$ & $\checkmark$ & $\checkmark$ & $\checkmark$ \\
\hline $\begin{array}{l}\text { Corneal } \\
\text { staining }\end{array}$ & $\checkmark$ & $\checkmark$ & & $v$ & $\checkmark$ \\
\hline $\begin{array}{l}\text { Conjunctival } \\
\text { staining }\end{array}$ & & & & $\checkmark$ & $\checkmark$ \\
\hline Lid redness & & & & $\checkmark$ & $\checkmark$ \\
\hline Lid swelling & & & & $\checkmark$ & $\checkmark$ \\
\hline TBUT & & & & $\checkmark$ & $\checkmark$ \\
\hline IOP & $\checkmark$ & $\nu$ & $v$ & $\checkmark$ & $\checkmark$ \\
\hline $\begin{array}{l}\text { Patient- } \\
\text { reported } \\
\text { signs }\end{array}$ & $\checkmark$ & $v$ & $\checkmark$ & 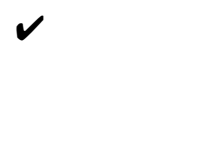 & \\
\hline $\begin{array}{l}\text { Patient } \\
\text { tolerability }\end{array}$ & $\checkmark$ & & $\checkmark$ & $\checkmark$ & $\checkmark$ \\
\hline $\begin{array}{l}\text { Patient } \\
\text { satisfaction }\end{array}$ & & & $\checkmark$ & $\checkmark$ & $\checkmark$ \\
\hline $\begin{array}{l}\text { 5-Parameter } \\
\text { score }\end{array}$ & & & & $\checkmark$ & $\checkmark$ \\
\hline
\end{tabular}

Observational study involved switching medications

TBUT tear film breakup time, IOP intraocular pressure

conjunctival staining (25), and tear film breakup time (TBUT) (20) (Table 2).

The weighting assigned to each of the ocular signs for the calculation of this score was defined by the expert authors. Other secondary objectives compared the IOP-lowering efficacy between medications and ocular signs and symptoms. Ocular signs and symptoms included eye dryness/tearing/foreign body sensation, irritation/stinging/burning, itching/sticky eye sensation, itching, red eye/lid redness, blurred vision, pain or discomfort, lid swelling, fluorescein staining (corneal and conjunctival), and TBUT.
Patient and investigator satisfaction with treatment were graded as "very unsatisfied", "unsatisfied", "satisfied", and "very satisfied".

\section{Statistical Analysis}

\section{Data Sources}

This pooled study was based on individual patient data (IPD) from the five studies (two phase III, one phase IV, and two real-world evidence studies). These studies were selected owing to common inclusion criteria: all patients included were diagnosed with glaucoma and treated with PL or PFL and there was complete information on conjunctival hyperemia and 
IOP. All relevant data from the individual datasets were combined into one dataset.

\section{Data Collection and Endpoints}

Data were collected on patient demographics including gender and age (Table 1), IOP for efficacy; conjunctival hyperemia and ocular signs for tolerability, patient satisfaction, and adverse events. For each individual study, all the data were collected and verified (Table 2).

Patients who did not meet inclusion and non-inclusion criteria were excluded from the analysis. Inclusion of IPD in the final database was verified by the investigator and the statistician. Improvement of conjunctival hyperemia was defined as a decrease in the grade of conjunctival hyperemia between baseline (day 0) and day 84 after initiating treatment.

\section{Analysis and Statistics}

Descriptive statistics were provided depending on the nature of the considered criterion: number of observed (and missing, if any) values, mean, standard deviation, median, first and third quartiles, as well as minimum and maximum, for quantitative data; number of observed (and missing, if any) values, number and percentage of patients for qualitative data. All data were presented as overall values according to the studies.

A pooled analysis of IPD was performed to analyze primary and secondary endpoints. Randomized clinical trials and observational studies were combined to produce this pooled analysis. Shrier et al. have demonstrated that combining data from randomized clinical trials and non-randomized clinical trials produces more relevant estimators, reducing bias and mitigating the limitations of each type of study [15].

Evaluation of the one-step and two-step approach yielded very similar results, indicating that the analysis was robust with either approach; hence, we elected to go with the twostep analysis. A two-step IPD pooled analysis approach was chosen as this approach allows the use of forest plots to estimate odds ratio (OR) and 95\% confidence intervals (CIs) and to illustrate heterogeneity and individual and pooled results. The $I^{2}$ statistic was used to determine heterogeneity, which measures inconsistency (percentage of total variation across studies due to heterogeneity) of effects. As a result of the different study designs (e.g., crossover, parallel group, randomized, naive patients, and switching between different medications), heterogeneity between studies was examined by checking the results of the $I^{2}$ statistic both for primary and secondary endpoint analyses. If heterogeneity was evident, it was incorporated using random effects modelling.

\section{Two-Step IPD Pooled Analysis}

The first step of the two-step IPD pooled analysis approach consists of analyzing the studies separately and individually. For each study, a logistic regression model was performed to provide estimates, variances, and covariances of the mean difference between treatments (including OR and 95\% CIs). Logistic regression was used with the presence or absence of improvement (for both endpoints) as the binary dependent variable and treatment as a categorical independent variable.

The second step of the two-step approach combines the study estimates. The variances and covariances obtained in the first step are used as the variance and covariance of the residual errors. All studies were weighted on the inverse of the variance (within- and betweenstudies variances) to obtain the results of the pooled analysis. For the IPD pooled analysis on the primary and secondary endpoints, statistical analysis was performed using SAS ${ }^{\circledR} 9.4$ software (SAS Institute Inc., Cary, NC, USA).

\section{RESULTS}

\section{Demographics Data}

The five studies enrolled a total of 3610 patients. Table 1 presents the patient demographics for the five studies enrolled and the combined data. The number of patients and the study variables differed between studies resulting in differences in the number of patients reported for the various variables reported in 


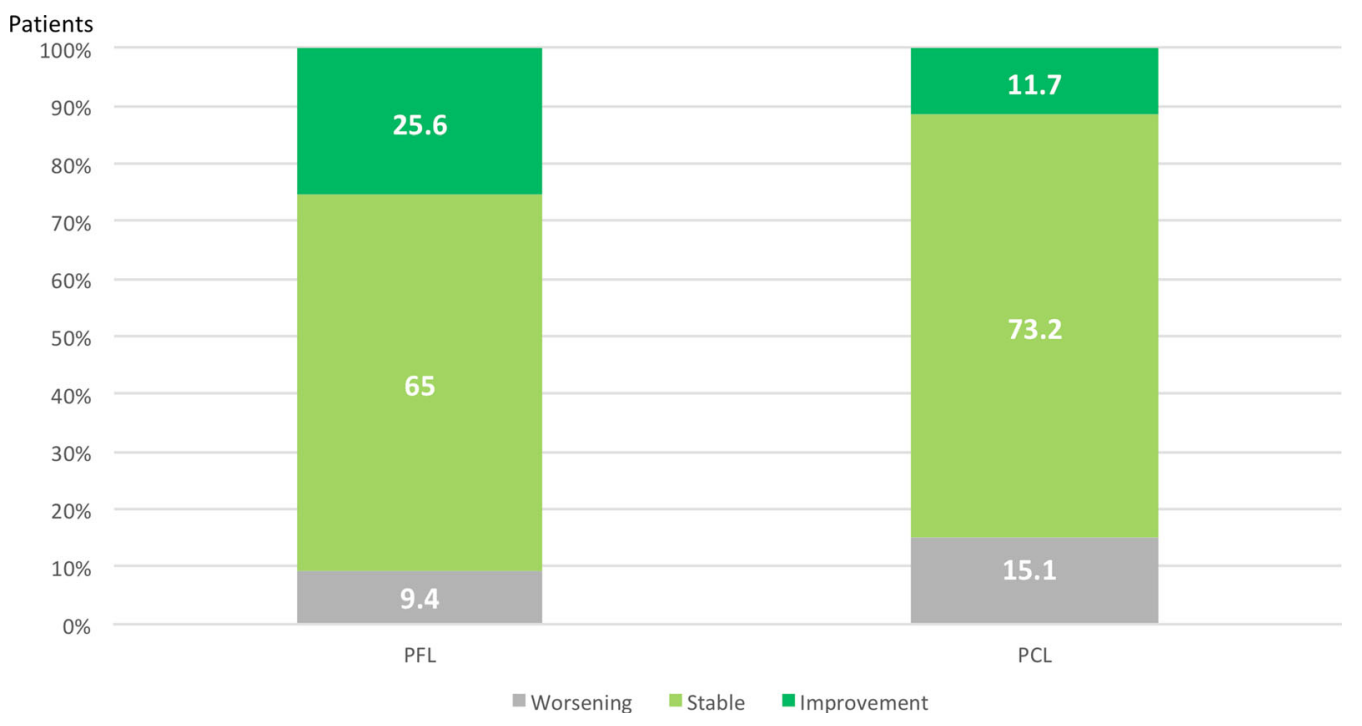

Fig. 1 Change in conjunctival hyperemia after switching latanoprost (PFL; Monoprost ${ }^{\circledR}:$ Laboratoires Théa, Clerto preservative-containing latanoprost (PCL; Xalatan ${ }^{\circledR}$ : mont-Ferrand, France)

Pfizer Inc., New York, NY, USA) or preservative-free

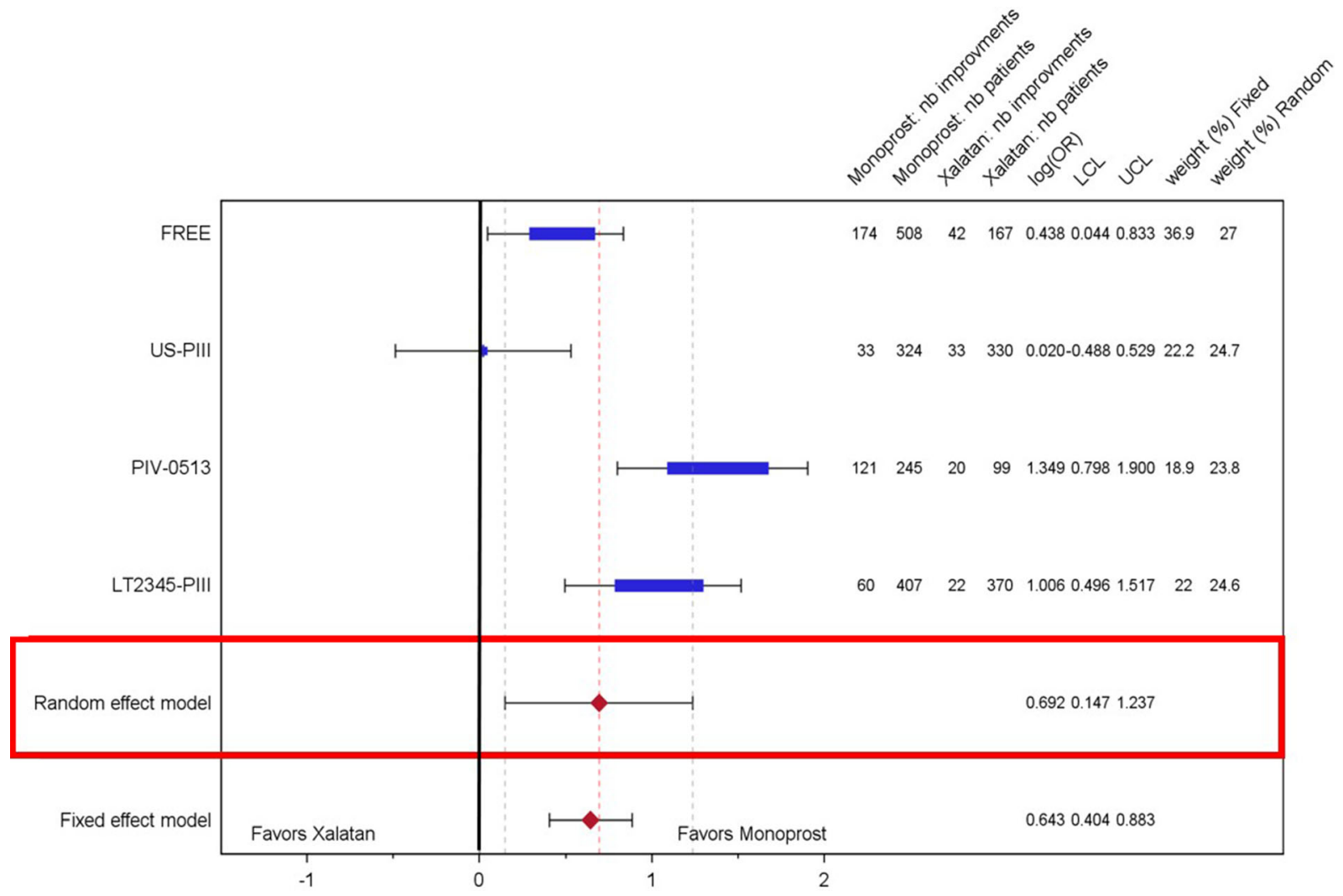

Fig. 2 Forest plot showing the effect of using preservative-containing (Xalatan ${ }^{\circledR}$ : Pfizer Inc., New York, NY, USA) or preservative-free latanoprost (Monoprost ${ }^{\circledR}$ : Laboratoires Théa, Clermont-Ferrand, France) on conjunctival hyperemia 
this study (Tables 1 and 2). The mean age of the patients and the gender distribution were similar between studies. There were 2769 (65.3\%) patients in the PFL group and 719 (16.9\%) patients in the PCL group, and 754 (17.8\%) patients were receiving other topical glaucoma therapy. At day 84, there were 1338 (57.4\%) patients in the PFL group and $568(24.3 \%)$ in the PCL group, and 427 (18.3\%) patients were receiving other topical glaucoma therapy.

\section{Conjunctival Hyperemia}

Figure 1 presents the grading of conjunctival hyperemia at baseline and day 84 for each group. Conjunctival hyperemia remained unchanged (stable) in $64.9 \%$ (982) of patients in the PFL group and in $73.2 \%$ (729) of patients in the PCL group (Fig. 1). Conjunctival hyperemia significantly improved in $25.6 \%$ (388) of patients switched to the PFL group and in $11.7 \%$ (117) of patients to the PCL group (Fig. 1; $p<0.001)$.

The two-step approach for ensuring validity of the current analyses of hyperemia generated estimates of 0.643 for fixed effects and 0.692 for the random effect model. The one-step

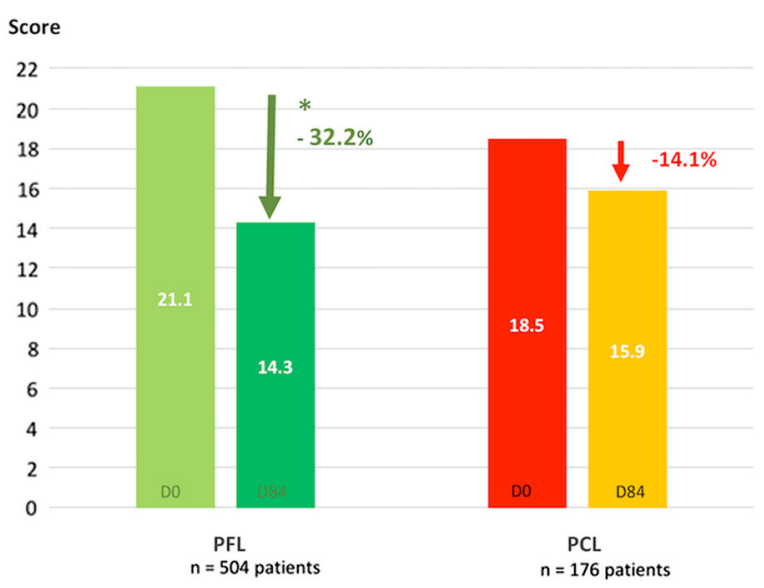

Fig. 3 Change in mean weighted five-parameter composite score of ocular signs and symptoms after switching to preservative containing latanoprost (PCL; Xalatan ${ }^{\circledR}$ : Pfizer Inc., New York, NY, USA) or preservative-free latanoprost (PFL; Monoprost ${ }^{\circledR}$ : Laboratoires Théa, Clermont-Ferrand, France). D0 denotes day 0 and D84 denotes day 84; ${ }^{*}$ Denotes statistically significant change, $p<0.001$ approach generated an estimate of 0.673 . The similar estimates for both approaches indicate strong validity of the results.

Figure 2 presents the forest plot with the fixed effect model and the random effect models for conjunctival hyperemia. Pooled analysis indicated PFL was two times superior to PCL group in reducing ocular hyperemia (odds ratio, 1.96; $p<0.001$ ) (Fig. 2). The sample size for each study is included in Fig. 2.

\section{Five-Parameter Ocular Surface Disease Composite Score}

There was a twice as significant decrease in ocular signs and symptoms in the PFL group $[-32.2 \% ;-6.8 \pm 10.8$ (range -67 to 17 ) compared to the PCL group $[-14.1 \%$; $-2.6 \pm 7.7$ (range -33 to 22)] (Fig. 3; $p<0.001)$.

\section{Patient Satisfaction}

At 3 months after initiating therapy, $95.7 \%$ (2671) of patients in the PFL group and $92.8 \%$ (305) of patients in the PCL group were very satisfied or satisfied with tolerating their topical eye drops.

\section{Ophthalmologist Satisfaction}

At 3 months, ophthalmologists were very satisfied or satisfied with patient tolerance of topical therapy for 362 of 368 (98.4\%) patients in the PFL group and for 348 of 351 (99.1\%) patients in the PCL group.

\section{Intraocular Pressure}

At baseline, the mean IOP was $19.1 \pm 4.00 \mathrm{mmHg}$ (range $9-35 \mathrm{mmHg}$ ) in the PFL group and $19.9 \pm 4.1$ (range $9-31 \mathrm{mmHg}$ ) in the PCL group. At day 84, the mean IOP was $16.1 \pm 2.8 \mathrm{mmHg}$ (range $6-30 \mathrm{mmHg}$ ) in the PFL group and $15.5 \pm 2.5$ (range $8-26 \mathrm{mmHg}$ ) in the PCL group. The change in IOP from baseline to day 84 was similar between groups $(p=0.312)$. The IC estimate was -0.103 for the 


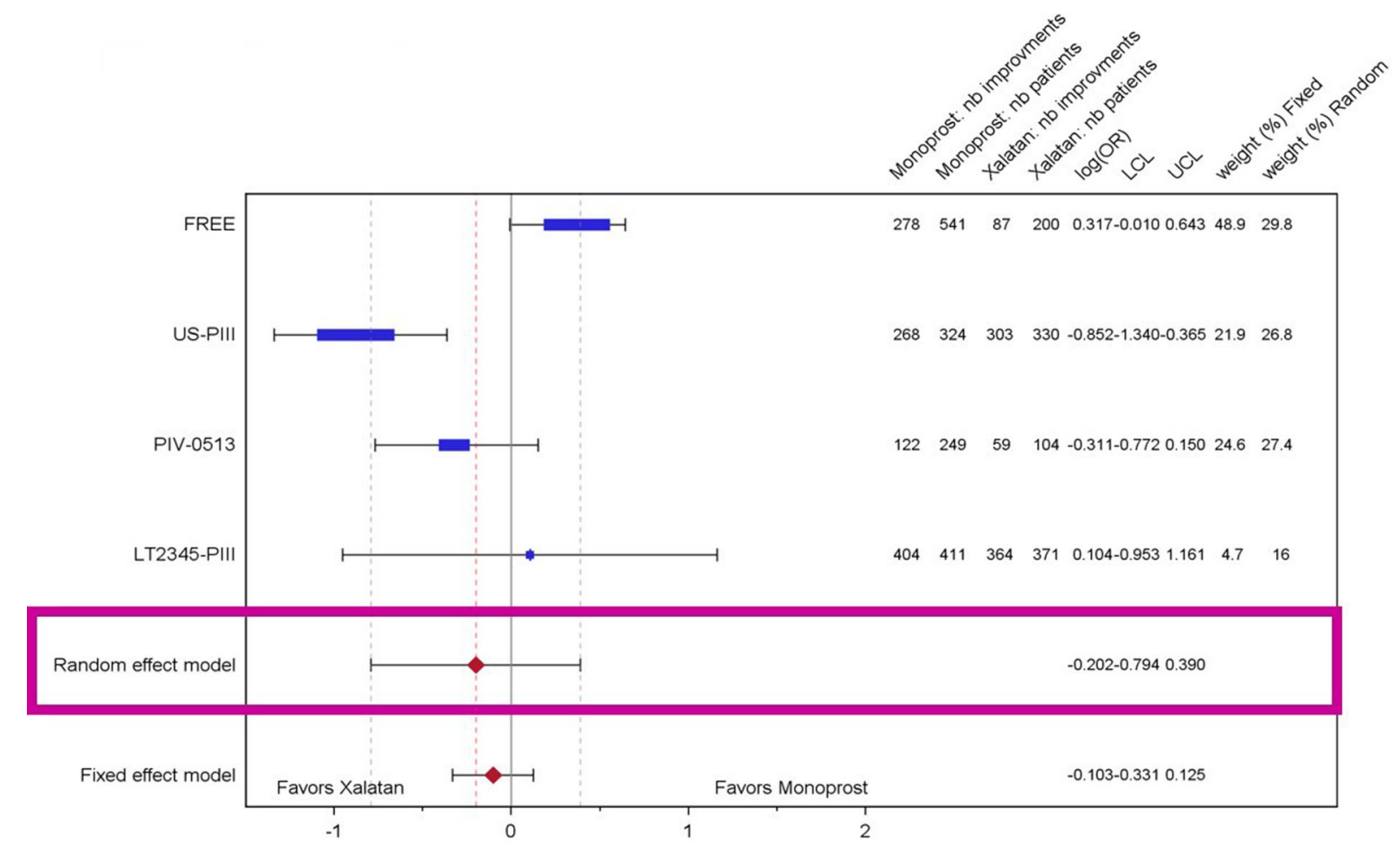

Fig. 4 Forest plot showing the effect of using preservative-containing latanoprost (Xalatan ${ }^{\circledR}$ ) or preservative-free latanoprost $\left(\right.$ Monoprost ${ }^{\circledR}$ ) on intraocular pressure

fixed effect model and -0.202 for the random effects model (Fig. 4).

\section{DISCUSSION}

This study involved a complete reanalysis of the source data of both observational studies and controlled clinical trials comparing preservative-free to preserved latanoprost for open-angle glaucoma. The inclusion of data from observational studies and clinical trials may aid in the clinical interpretation and in establishing causal inferences [15]. Additionally, the combination of randomized controlled trials and real-world evidence observational studies may increase the precision and allow more clinically valid outcomes for the topic being investigated $[15,16]$. In the current analysis, estimates from the 1-step and 2-step approach (fixed and random effects models) resulted in very similar estimates. This outcome indicates that the statistical methods were very robust and appropriate for this comparison of PFL and PCL.
The outcome of this post hoc pooled analysis of the published studies indicates that PFL is better tolerated and as efficacious at reducing IOP as PCL. Topical PFL was twice as effective at reducing conjunctival hyperemia at 3 months compared to topical PCL $(p<0.001)$. This statistically significant decrease confirmed that removing the preservative benzalkonium chloride (BAK) improved conjunctival hyperemia. The forest plot indicated that the majority of studies favor the preservative-free formulation of latanoprost (Monoprost ${ }^{\circledR}$ ) for reducing ocular hyperemia. These outcomes concur with Cucherat et al.'s meta-analyses of PFL versus a number of other preservative-containing PGAs including PCL $\left(\right.$ Xalatan $\left.^{\circledR}\right)$ [16]. They reported that PFL carried a statistically significantly lower risk of hyperemia compared to all the other PGAs [16]. Cucherat and colleagues concluded that PFL was better tolerated than all the other PGAs [16]. Additionally, animal studies of BAK indicate that it was found in deeper structures 
that are affected by glaucoma such as the trabecular meshwork and the optic nerve $[2,3]$.

In the current study, the weighted five-parameter OSD composite score indicated a 32.2\% decrease in ocular signs and symptoms (eyelid redness and corneal and conjunctival staining and TBUT) in the PFL group compared to a $14.1 \%$ decrease in the PCL group. This outcome indicates that PFL was twice as efficient at reducing the OSD composite score compared to the PCL group after switching treatments. This is the first publication that reports a five-parameter OSD composite score to quantify the global clinical changes in the ocular surface. We believe that using a five-parameter OSD score is much more clinically relevant compared to using only one or two tolerability parameters. This score may serve as a useful metric for quantifying OSD in future studies.

Preservatives disrupt the ocular surface by numerous mechanisms including cellular apoptosis and neurotoxicity causing OSD and reducing patient tolerability $[6,7,19,20]$. Furthermore, preservatives may cause some local corneal anesthesia masking the symptoms of OSD that may increase severity over time $[17,21,22]$. Reduced patient tolerability can lead to decreased patient compliance or discontinuation of glaucoma therapy, further reducing the intended therapeutic effect [23]. Taken together, the reduced hyperemia and the mitigation of ocular signs with PFL should result in greater patient tolerability of the treatment and, potentially, a better health-related quality of life [24, 25].

The increased patient tolerance has been reported to result in greater patient satisfaction with topical therapy $[13,22]$. In the current study, patient satisfaction to both formulations was very high (greater than 92\%). Ophthalmologists were also very satisfied or satisfied with the efficacy of both formulations in over 93\% of their patients. This observation indicates that ophthalmologists considered PFL had similar IOP-lowering effects to PCL. A recent international study of preserved glaucoma medications reported that despite high patient satisfaction, various ocular signs were reported in $10.3-42.5 \%$ of 793 patients that resulted in low tolerance to preserved medications [26].
Hence preservative-free formulations may allow greater patient tolerance which is likely to lead to better long-term compliance with therapy resulting in greater long-term efficacy of glaucoma therapy.

In the current study, the IOP decrease at 3 months after initiating or starting treatment was similar between groups, indicating a similar efficacy of the preserved and preservative-free formulations. The change in IOP is similar to previous publications of PCL [27]. Some have postulated that the disruption of the corneal epithelium by preservatives may allow greater therapeutic efficacy of topical ophthalmic medications [28]. Our results, however, concur with Misiuk-Hojlo and colleagues who reported very similar IOP-lowering effects with PFL and PCL [29]. This observation concurs with a previous meta-analysis of PFL to preserved PGAs that found similar or better IOP-lowering efficacy with PFL [16].

One of the potential limitations in the study is that the patients were asked about satisfaction with their treatment by their own ophthalmologists and patients may minimize their symptoms to avoid disappointing their doctors. However, further research and direct RCT are warranted to support the improvement linked to the use of PF treatments. The current study is innovative in the ophthalmic literature, by providing a pooled analysis of randomized comparative trials and observational studies. However, similar pooled analyses of randomized and observation studies have been recently published in other fields of medicine without significant concerns that incorporation of observational studies might skew the pooled analysis [30-32]. Similar to the aforementioned studies, our study protocol and statistical analyses (detailed in "Methods") incorporated measures to address heterogeneity between studies and response-surface estimation to accommodate the effect of bias from any cause including study design [15, 30-34]. Shrier et al. have previously addressed the advantages of combining randomized and non-randomized studies, including mitigating limitations of each design and increased sample size [15]. However, we are limited to reporting the outcomes of this study 
as there is no previous pooled analysis comparison in the current ophthalmic literature.

\section{CONCLUSIONS}

Switching to latanoprost preservative-free formulation was twice as effective as the preserved formulation at reducing ocular hyperemia. Additionally, PFL is twice as efficient at reducing ocular signs such as eyelid redness and corneal and conjunctival staining and TBUT. The IOP-lowering efficacy of PFL is similar to PL. Further studies are warranted to confirm that the improved signs and symptoms from PFL can lead to better patient tolerability improving treatment compliance and potentially maintaining the long-term efficacy of the medication.

\section{ACKNOWLEDGEMENTS}

Funding. Laboratoires Théa paid for statistical analysis, medical writing and the journal's Rapid Service Fee.

Authorship. All named authors meet the International Committee of Medical Journal Editors (ICMJE) criteria for authorship for this article, take responsibility for the integrity of the work as a whole, and have given their approval for this version to be published.

Authors' Contributions. All authors have given final approval of this version to be published. Paul Harasymowycz, Cindy Hutnik, Jean-François Rouland, Francisco J. Muñoz Negrete, Mario A. Economou, Philippe Denis, Christophe Baudouin participated in drafting the manuscript, study design, data collection and screening, data-analysis and evidence synthesis, and revising the manuscript. Paul Harasymowycz, Cindy Hutnik, Christophe Baudouin, Jean-François Rouland participated in literature search, data collection, data-analysis and evidence synthesis and drafting the manuscript. Paul Harasymowycz, Cindy Hutnik and Christophe Baudouin participated in hypothesis generation, evidence synthesis and revising the manuscript. Paul Harasymowycz, Cindy Hutnik, Jean-François Rouland, Francisco J. Muñoz Negrete, Mario A. Economou, Philippe Denis, Christophe Baudouin participated in study design, data collection, screening and revising the manuscript.

Disclosures. Paul Harasymowycz has served as a consultant and/or received research grants from Allergan, Alcon, Aequus Pharma, Aerie, Bausch Health, Novartis, Santen, Laboratoires Théa. Cindy Hutnik has served as a consultant and/or received research grants from Allergan, Alcon, Aequus Pharma, Aerie, Laboratoires Théa, Bausch Health and Novartis. Jean-François Rouland served as a consultant for Allergan, Eyetechcare, Horus, Santen and Laboratoires Théa. Francisco J. Muñoz Negrete has served as a consultant and/or received research grants from Alcon, Avizor, Bayer, Esteve, Laboratoires Théa, Santen. Mario A. Economou received honoraria from Laboratoires Théa for participation in the study and is consultant to Laboratoires Théa. Philippe Denis has served as a consultant for Novartis, Laboratoires Théa, EyeTechCare Aerie and iStar. Christophe Baudouin has served as a consultant and/or received research grants from Aerie, Alcon, Allergan, Horus Pharma, Santen and Laboratoires Théa, and received personal fees from Alcon, Allergan, Aerie and grants and personal fees from Laboratoires Théa, Santen, and Horus Pharma.

Compliance with Ethics Guidelines. The source data from each of the five studies were acquired and re-analyzed in a new database. Each study was approved by the ethics review board in each country and adhered to the tenets of the Declaration of Helsinki and all relevant local regulations. As this is a review of data from previous studies, online registration as a clinical trial was not required.

Data Availability. The datasets generated during and/or analyzed during the current study are not publicly available because this is retrospective review of previous studies. 
Open Access. This article is licensed under a Creative Commons Attribution-NonCommercial 4.0 International License, which permits any non-commercial use, sharing, adaptation, distribution and reproduction in any medium or format, as long as you give appropriate credit to the original author(s) and the source, provide a link to the Creative Commons licence, and indicate if changes were made. The images or other third party material in this article are included in the article's Creative Commons licence, unless indicated otherwise in a credit line to the material. If material is not included in the article's Creative Commons licence and your intended use is not permitted by statutory regulation or exceeds the permitted use, you will need to obtain permission directly from the copyright holder. To view a copy of this licence, visit http://creativecommons.org/licenses/by$\mathrm{nc} / 4.0 /$.

\section{REFERENCES}

1. Stalmans I, Sunaric MG, Cordeiro MF, et al. Preservative-free treatment in glaucoma: who, when, and why. Eur J Ophthalmol. 2013;23:518-25.

2. Brignole-Baudouin F, Desbenoit N, Hamm G, et al. A new safety concern for glaucoma treatment demonstrated by mass spectrometry imaging of benzalkonium chloride distribution in the eye, an experimental study in rabbits. PLoS One. 2012;7: e50180.

3. Bouchemi M, Roubeix C, Kessal K, et al. Effect of benzalkonium chloride on trabecular meshwork cells in a new in vitro 3D trabecular meshwork model for glaucoma. Toxicol In Vitro. 2017;41: 21-9.

4. Baudouin C, Renard JP, Nordmann JP, et al. Prevalence and risk factors for ocular surface disease among patients treated over the long term for glaucoma or ocular hypertension. Eur J Ophthalmol. 2013;23:47-54.

5. Leung EW, Medeiros FA, Weinreb RN. Prevalence of ocular surface disease in glaucoma patients. J Glaucoma. 2008;17:350-5.

6. Hutnik C, Neima D, Ibrahim F, et al. Tolerability and effectiveness of preservative-free dorzolamidetimolol (preservative-free COSOPT) in patients with open-angle glaucoma or ocular hypertension. Clin Ophthalmol. 2010;4:581-90.

7. Thygesen J. Glaucoma therapy: preservative-free for all? Clin Ophthalmol. 2018;12:707-17.

8. Wolfram C, Stahlberg E, Pfeiffer N. Patient-reported nonadherence with glaucoma therapy. J Ocul Pharmacol Ther. 2019;35:223-8.

9. Economou MA, Laukeland HK, Grabska-Liberek I, et al. Better tolerance of preservative-free latanoprost compared to preserved glaucoma eye drops: the 12-month real-life FREE study. Clin Ophthalmol. 2018;26(12):2399-407.

10. Harasymowycz P, Birt C, Gooi P, et al. Medical management of glaucoma in the 21st century from a Canadian perspective. J Ophthalmol. 2016;2016: 6509809.

11. Denis P, Monoprost French Study Group. [Unpreserved latanoprost in the treatment of open-angle glaucoma and ocular hypertension. A multicenter, randomized, controlled study]. J Fr Ophtalmol. 2016;39:622-30.

12. Aspberg J, Heijl A, Jóhannesson G, et al. Intraocular pressure lowering effect of latanoprost as first-line treatment for glaucoma. J Glaucoma. 2018;27(11): 976-80.

13. Muñoz Negrete FJ, Lemij HG, Erb C. Switching to preservative-free latanoprost: impact on tolerability and patient satisfaction. Clin Ophthalmol. 2017;11: 557-66.

14. Rouland JF, Traverso CE, Stalmans I, et al. Efficacy and safety of preservative-free latanoprost eyedrops, compared with BAK-preserved latanoprost in patients with ocular hypertension or glaucoma. Br J Ophthalmol. 2013;97:196-200.

15. Shrier I, Boivin JF, Steele RJ, et al. Should metaanalyses of interventions include observational studies in addition to randomized controlled trials? A critical examination of underlying principles. Am J Epidemiol. 2007;15(166):1203-9.

16. Cucherat M, Stalmans I, Rouland JF. Relative efficacy and safety of preservative-free latanoprost (T2345) for the treatment of open-angle glaucoma and ocular hypertension: an adjusted indirect comparison meta-analysis of randomized clinical trials. J Glaucoma. 2014;23:e69-75.

17. Martone G, Frezzotti P, Tosi GM, et al. An in vivo confocal microscopy analysis of effects of topical antiglaucoma therapy with preservative on corneal innervation and morphology. Am J Ophthalmol. 2009;147(725-735):e1. 
18. Baudouin C, Barton $\mathrm{K}$, Cucherat $\mathrm{M}$, et al. The measurement of bulbar hyperemia: challenges and pitfalls. Eur J Ophthalmol. 2015;25:273-9.

19. Baudouin C, Labbé A, Liang H, et al. Preservatives in eyedrops: the good, the bad and the ugly. Prog Retin Eye Res. 2010;29:312-34.

20. Baudouin C, Denoyer A, Desbenoit N, et al. In vitro and in vivo experimental studies on trabecular meshwork degeneration induced by benzalkonium chloride (an American Ophthalmological Society thesis). Trans Am Ophthalmol Soc. 2012;110: 40-63.

21. Van Went C, Alalwani H, Brasnu E, et al. Evaluation de la sensibilite corneenne chez les patients traites medicalement pour un glaucome ou une hypertonie oculaire [Corneal sensitivity in patients treated medically for glaucoma or ocular hypertension]. J Fr Ophtalmol. 2011;34:684-690 (in French).

22. Lemij HG, Hoevenaars JG, van der Windt C, et al. Patient satisfaction with glaucoma therapy: reality or myth? Clin Ophthalmol. 2015;9:785-93.

23. Beckers HJ, Schouten JS, Webers CA, et al. Side effects of commonly used glaucoma medications: comparison of tolerability, chance of discontinuation, and patient satisfaction. Graefes Arch Clin Exp Ophthalmol. 2008;246:1485-90.

24. Jaenen N, Baudouin C, Pouliquen P, et al. Ocular symptoms and signs with preserved and preservative-free glaucoma medications. Eur J Ophthalmol. 2007;17:341-9.

25. Pisella PJ, Pouliquen P, Baudouin C. Prevalence of ocular symptoms and signs with preserved and preservative free glaucoma medication. Br J Ophthalmol. 2002;86:418-23.

26. Stalmans I, Lemij H, Clarke J, Baudouin C, GOAL study group. Signs and symptoms of ocular surface disease: the reasons for patient dissatisfaction with glaucoma treatments. Clin Ophthalmol. 2020;14: 3675-3680.

27. Tang W, Zhang F, Liu K, et al. Efficacy and safety of prostaglandin analogues in primary open-angle glaucoma or ocular hypertension patients: a metaanalysis. Medicine (Baltimore). 2019;98:e16597.

28. Majumdar S, Hippalgaonkar K, Repka MA. Effect of chitosan, benzalkonium chloride and ethylenediaminetetraacetic acid on permeation of acyclovir cross isolated rabbit cornea. Int J Pharm. 2008;348: $175-8$.

29. Misiuk-Hojlo M, Pomorska M, Mulak M, et al. The RELIEF study: tolerability and efficacy of preservative-free latanoprost in the treatment of glaucoma or ocular hypertension. Eur J Ophthalmol. 2019;29: 210-5.

30. Rim CH, Shin IS, Lee HY, et al. Oncologic benefit of adjuvant chemoradiation after D2 gastrectomy: a stepwise hierarchical pooled analysis and systematic review. Cancers (Basel). 2020;12:2125.

31. Tlayjeh $\mathrm{H}$, Mhish $\mathrm{OH}$, Enani MA, et al. Association of corticosteroids use and outcomes in COVID-19 patients: a systematic review and meta-analysis. J Infect Public Health. 2020;S1876-0341:30663-8.

32. Lalieu RC, Brouwer RJ, Ubbink DT, et al. Hyperbaric oxygen therapy for nonischemic diabetic ulcers: a systematic review. Wound Repair Regen. 2020;28: 266-75.

33. Greenland $\mathrm{S}, \mathrm{O}^{\prime}$ Rourke $\mathrm{K}$. On the bias produced by quality scores in meta-analysis, and a hierarchical view of proposed solutions. Biostatistics. 2001;2: 463-71.

34. Vanhonacker WR. Meta-analysis and response surface extrapolation: a least squares approach. Am Stat. 1996;50:294-9. 